\title{
Beyond "Normal": Optimal Levels of Medical Parameters for Assessing Positive Health
}

\author{
Abhaya Indrayan ${ }^{1, ~ *, ~ G a y a t r i ~ V i s h w a k a r m a ~}{ }^{2}$, Sanjeev Sarmukaddam ${ }^{3}$, Saumya Verma ${ }^{1}$ \\ ${ }^{1}$ Department of Clinical Research, Max Healthcare, New Delhi, India \\ ${ }^{2}$ Department of Biostatistics, Indian Spinal Injuries Centre, New Delhi, India \\ ${ }^{3}$ Department of Biostatistics, BJ Medical College, Pune, India
}

Email address:

a.indrayan@gmail.com (A. Indrayan)

${ }^{*}$ Corresponding author

\section{To cite this article:}

Abhaya Indrayan, Gayatri Vishwakarma, Sanjeev Sarmukaddam, Saumya Verma. Beyond "Normal": Optimal Levels of Medical Parameters for Assessing Positive Health. American Journal of Internal Medicine. Vol. 9, No. 4, 2021, pp. 166-170. doi: 10.11648/j.ajim.20210904.12

Received: June 13, 2021; Accepted: June 26, 2021; Published: June 30, 2021

\begin{abstract}
Background: Whereas the concept of normal levels of various parameters is extensively used in medical practice, the concept of optimal levels has not received much attention. We propose that it is time to pay attention to the optimal levels so that positive health can be measured. Objective: The objective is to define optimal levels of medical parameters as that combination which prevents the occurrence of ailments or gives strength to fight these ailments if they occur. Methods: A large number of articles and other literature was reviewed in search of medical parameters and their levels that could be considered to indicate optimal levels. Result: The optimal combination of medical parameters that prevents occurrence of ailments and gives strength to fight if an ailment occurs, is conceptually beyond the 'normal' levels that we use in everyday clinical practice and can be considered to indicate positive health. This is illustrated with the help of several examples after dividing the concept of positive health into five domains on the pattern of quality-of-life assessment. Conclusion: A concept of positive health has been proposed and its link to the optimal level of medical parameters is described. We plead that more efforts be made to identify the positive parameters of health, and their optimal levels that measure positive health be delineated.
\end{abstract}

Keywords: Beyond Normal, Normal Levels, Optimal Levels, Positive Health

\section{Introduction}

The oft quoted and perhaps the most widely accepted definition of health is "a state of complete physical, mental and social well-being and not merely the absence of disease or infirmity". [1] However, this is utopian and an unattainable ideal. [2] On the ground, health can be defined as that state of dynamic equilibrium of body, mind, and soul, when homeostasis is going on well and the person is able to carry out the routines of life without inhibition. This may be the most direct definition of "normal" health, although there is no consensus on what is normal in health and medicine. [3]

Health abnormality occurs when an ailment strikes that disrupts the equilibrium and impedes the routine of life in any manner. Diseases, injuries, impairments, and psychological disturbances are examples of such ailments. Conventional medicine can be understood as the remedial measures taken to put the body systems back on track when a derailment occurs. Thus, medical science is mostly oriented to relieving suffering and restoring health to its normal state. The steps for prevention of ailments and promotion of health are separate from this conventional view of medicine although the terms such as preventive medicine and promotive medicine are also common in medical parlance.

The aim of the present communication is to present the concept of positive health as beyond 'normal' that signifies that the body systems are working at optimal level to prevent ailments and their adverse consequences if they occur.

\section{Positive Health}

Some people fall sick frequently and die early while some rarely fall sick and die late. Positive health can be considered as a state when the person is not just healthy but has 
sufficient reserves to fight the illness if and when that strikes and is able to carry out the routines of life in a normal manner in adverse situations. This implies the availability of mechanisms in the body to thwart the ailments and to minimize their adverse effect if they strike. The implication of positive health is living long in good health.

The earliest reference we could locate to the concept of positive health is the sense we present in this communication is in a 2001 book where positive health is described as the ability to cope with biological, psychological, and social stress, with parameters such as pain-bearing capacity and vital capacity as its indicators. [4] Seligman in 2008 provided another version and operationalized it by a combination of excellent status on biological, subjective, and functional measures. [5] He included factors such as optimism, stable marriage, and lower blood pressure level. [6]

Our focus is on body elements and functions that harness the body's capacity to fight any adversity and be able to maintain homeostasis at an adequate level in adverse situations, in addition to maintaining normal health. Distal factors such as genes, diet, exercise, sleep, and social interaction are indeed relevant and appealing, but we do not consider them in our framework because these are mostly subjective, highly volatile, and defy measurement. Instead, we restrict to proximal parameters of the body's internal mechanisms, particularly those that are measurable and relatively more stable, so that an objective assessment of the level of positive health can be made. There is a plenty of evidence that these distals modulate various medical parameters such as immunity level and hormonal balance that shield from ailments. For example, genes are involved in hormonal signaling, [7] exercise reduces the level of stress hormones such as adrenaline and cortisol and stimulates the production of endorphins, [8] nutrition modulates immune functions, [9] and sleep influences the cardiovascular endocrine and thermoregulatory system. [10]

Although the normal level of various parameters is important for positive health, our emphasis is on the optimal level of parameters and markers that protect from disease. We realize that disentangling of physiological and neurological pathways that lead to positive health would be a challenging task but at least a beginning can be made.

\section{Domains of Positive Health}

The concept of positive health may be easier to comprehend when divided into domains and items on the pattern of quality of life. As in the case of quality of life, these domains do not work in isolation. They affect one another, and the overlap is substantial. For items within each domain, we restrict to objectively measurable parameters instead of images and invasive investigations.

The most prominent domain of positive health is the adequate level of immunity that helps battle the infection and protects us from several ailments. The immune system identifies and destroys foreign elements such as microbes, [11] which can disturb homeostasis and produce disease. The domain of immunity includes items such as the optimal level of immunoglobulins, lymphocytes (B-cells and T-cells), macrophages, neutrophils, and dendritic cells.

The next most important domain perhaps is the optimal combination of nutritional elements in the body. This includes items such as the levels of various vitamins, minerals, fatty acids, and probiotics that have a salutary role in protection from several diseases, besides protein, carbohydrates, and other elements. For example. National Research Council Committee on Diet and Health [12] has extensively discussed how nutritional elements can help in preventing some chronic diseases, although the data are incomplete. Nevertheless, it is known that an appropriate combination of vitamins and minerals can protect from cancer. [13] Different vitamins help in making antibodies that fight disease, [14] build bone health, [15] and help fight infections and protect from damage to body cells, [16] and serve as antioxidants to protect from various diseases as we age. [17] The role of trace elements in the maintenance of immune functions is being increasingly recognized. [18] Zinc lowers oxidative stress, [19] probiotics can cut the number of respiratory infections, [20] and electrolytes help the body to maintain fluid and blood volume for it to function normally. [21] Convincing evidence exists that antioxidants and essential minerals are indispensable for a healthy mind and body. [22]

The third domain comprises items such as hormones, endorphins, enzymes, amino acids, and such other substances. Schwartz and Holtorf [23] have discussed the role of hormones in wellness and disease prevention. For example, melatonin is widely reported to exhibit protective effect in various diseases[24] besides controlling the sleep and wake cycle, [25] oxytocin helps with lactation and childbirth, [26] parathyroid hormone controls calcium levels in bones and blood, [27] testosterone contributes to sex drive and body density, [28] and serotonin regulates anxiety, happiness, mood, sleep, appetite, memory, and learning ability[29] and regulates biological process including cardiovascular functions, metabolic rate, and temperature control. [30] Endorphins control the perception of pain and fight stress, [31] and enzymes support, maintain, and repair the body and its functions. [32] Amino acids stimulate muscle synthesis. [33] An optimal combination of these and such other parameters may be effective in warding off many ailments or in controlling adverse effects of some ailments when they occur.

The set of neurological parameters is the fourth domain of positive health. Besides preventing neurological diseases such as Alzheimer's, dementia, anxiety, vertigo, aneurism, and epilepsy, these parameters control physiological processes required for normal brain functions and neuronal support while working with other parameters. [34] The nervous system controls brain growth and development, sensations, perception, emotions, memory, response to stress, and several others, including pain tolerance. [35] Neurological parameters may be among the most difficult to identify and measure and may have considerable overlap 
with hormones and other parameters. Whereas neurological assessment is mostly done through sensory and cerebellar investigations, search is on for substances in the blood that would indicate cognitive functions. [36] Among others, neural tissue markers such as microtubule-associated protein2 (MAP-2), S100B protein, [37] neuron-specific enolase (NSE), and tumor necrosis factor (TNF) can also help in determining the level of positive health on neurological parameters. P300 is considered an important maker of cognitive function [38].

The fifth and the last domain of positive health in our framework is the whole gamut of physiological and biochemical parameters. Most of the routine laboratory-based investigations fall in this domain. This includes parameters that protect from diseases of various organs, those that measure the adequacy of reproductive functions, and those that indicate the status of spine, bones, and muscles. This domain also includes parameters such as body mass index (BMI) and handgrip strength. The emphasis here also would not be on their normal levels but on optimal levels that provide a buffer against ailments. This may include low levels of substances such as bilirubin, total cholesterol, aspartate aminotransferase (AST), alanine aminotransferase (ALT), very low-density lipoprotein, troponin, prostatespecific antigen, rheumatoid factor, and high levels of parameters such as omega-3 fatty acids, bone mineral density (BMD), lung functions, and handgrip strength. Elevated levels of C-reactive protein (CRP), D-dimer, interleukin-6 (IL-6), and such other cytokines are associated with all-cause mortality [39], implying that their low level may help in avoiding mortality. Low levels of these markers may also help preserve brain health and support successful aging. [40]

\section{Discussion}

The term "positive health" has been talked about in several different contexts but possibly never precisely defined. We have proposed a definition as the one that can protect from ailments and helps in successfully fight the disease if that strikes. This may mean an optimal combination of various parameters, but it seems that such a combination is not known yet. Our proposal may be ahead of time because many of the defense mechanisms are still under study. The link between physiological processes and negative outcomes is fairly well known but the link with positive outcomes seems to have not been fully investigated. Some knowledge is available on substances that protect from diseases, but the optimal combination required for sufficient protection is mostly not known. We believe it is time to identify parameters that can contribute to our understanding of how body functions work to defend from ailments and fill up this epistemic uncertainty. [41] This can go a long way in taking steps to improve the health of the people. A step ahead would be to identify the optimal level factors that not just protect but promote health where promotion signifies better health in terms of increased capacity to work and to be able to bear an increased level of stress while living long.

\section{Limitations}

We realize that we may have just scratched the surface and not gone into sufficient details. Our review of the literature may be selective yet suggests that not much is known about the optimal combination of the levels of various parameters that is enough to protect health. We may not have been comprehensive in our description of even the known factors and some crucial aspects that affect health may have been missed. The purpose of this communication is to propose an idea and show that it is useful and feasible although we agree that much work is required to make it operational in the actual setup.

\section{Conclusion}

A feasible idea of positive health of individuals has been proposed that goes beyond 'normal'. We contend that the optimal level of some major proximal factors could be adequate to proceed ahead with the idea of positive health and leave the complexities for future workers. The proposal may help in identifying the data gaps that can be used to inform policies for improving the health of the people so that they develop the ability to thwart ailments and live long in good health. The proposal can also later lead to a scale that can be used to quantitatively measure positive health of individuals on an objective basis. In course of time, the concept can be extended to include parameters that promote health where promotion is enhancing the functionality level of the individuals.

\section{References}

[1] World Health Organization. Constitution of the World Health Organization-basic documents. 2006. Available at: https://www.who.int/governance/eb/who_constitution_en.pdf last accessed 25 April 2021.

[2] Misselbrook D. W is for wellbeing and the WHO definition of health. Brit $J$ Gen Practice. 2014; 64[628]:582. https://pubmed.ncbi.nlm.nih.gov/25348979/

[3] Catita M, Águas A, Morgado P. Normality in medicine: a critical review. Philos Ethics Humanit Med. 2020; 15[1]:3. https://www.ncbi.nlm.nih.gov/pmc/articles/PMC7161186/

[4] Indrayan A, Sarmukaddam S. Medical Biostatistics [First Edition]. Marcel \& Dekker, 2001; 164.

[5] Seligman MEP. Positive health. Applied Psychology: An International Review 2008; 57: 3-18. https://iaapjournals.onlinelibrary.wiley.com/doi/10.1111/j.14640597.2008.00351.x

[6] Positive Health: Researching strengths that contribute to good health and protect against illness. Available at: https://positivehealthresearch.org/ - last accessed 25 April 2021.

[7] Harden KP, Klump KL. Introduction to the special issue on gene-hormone interplay. Behav Genet. 2015; 45[3]:263-7. Epub 2015. https://pubmed.ncbi.nlm.nih.gov/25903987/ 
[8] Harvard Medical School. Exercising to relax. Harvard Health Publishing, 2020. Available at: https://www.health.harvard.edu/staying-healthy/exercising-torelax - last accessed 25 April 2021.

[9] Childs CE, Calder PC, Miles EA. Diet and immune function.

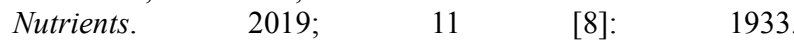
https://www.ncbi.nlm.nih.gov/pmc/articles/PMC6723551/

[10] Schwimmer H, Stauss HM, Abboud F, Nishino S, Mignot E, Zeitzer JM. Effects of sleep on the cardiovascular and thermoregulatory systems: A possible role for hypocretins. $J$ Appl Physiol [1985]. 2010; 109 [4]: 1053-63. Epub 2010. PMID: 20705949.

https://www.ncbi.nlm.nih.gov/pmc/articles/PMC5243202/

[11] Thompson AE. The Immune System. JAMA. 2015; 313 [16]: 1686.

https://jamanetwork.com/journals/jama/fullarticle/2279715

[12] National Research Council [US] Committee on Diet and Health. Diet and Health: Implications for reducing chronic disease risk. Washington [DC]: National Academies Press [US]; $1989 . \quad$ Available at: https://pubmed.ncbi.nlm.nih.gov/25032333/ - last accessed 25 April 2021

[13] Greenlee H. Natural products for cancer prevention. Semin Oncol Nurs. 2012; 28 [1]: 29-44. https://pubmed.ncbi.nlm.nih.gov/22281308/

[14] Rall LC, Meydani SN. Vitamin B6 and immune competence. Nutr Rev. 1993; 51 [8]: 217-25. https://pubmed.ncbi.nlm.nih.gov/8302491/

[15] Laird E, Ward M, McSorley E, Strain JJ, Wallace J. Vitamin D and bone health: Potential mechanisms. Nutrients. 2010; 2 [7]: 693-24.

https://www.ncbi.nlm.nih.gov/pmc/articles/PMC3257679/

[16] Chambial S, Dwivedi S, Shukla KK, John PJ, Sharma P. Vitamin $\mathrm{C}$ in disease prevention and cure: an overview. Indian $J$ Clin Biochem. 2013; 28 [4]: 314-28. https://www.ncbi.nlm.nih.gov/pmc/articles/PMC3783921/pdf/ 12291_2013_Article_375.pdf

[17] Rizvi S, Raza ST, Ahmed F, Ahmad A, Abbas S, Mahdi F. The role of vitamin $\mathrm{E}$ in human health and some diseases. Sultan Qaboos Univ Med J. 2014; 14 [2]: e157-65. https://www.ncbi.nlm.nih.gov/pmc/articles/PMC3997530/

[18] Chandra S, Chandra RK. Nutrition, immune response, and outcome. Prog Food Nutr Sci. 1986; 10 [1-2]: 1-65. https://pubmed.ncbi.nlm.nih.gov/3097756/

[19] Prasad, A.S. Zinc in human health: Effect of zinc on immune cells. Mol Med 2008; 14:353-7. https://doi.org/10.2119/200800033

[20] Wang Y, Li X, Ge T, et al. Probiotics for prevention and treatment of respiratory tract infections in children: A systematic review and meta-analysis of randomized controlled trials. Medicine [Baltimore]. 2016; 95 [31]: e4509. https://www.ncbi.nlm.nih.gov/pmc/articles/PMC4979858/pdf/ medi-95-e4509.pdf

[21] CDC. The role of potassium and sodium in your diet. Centers for Disease Control and Prevention. Available at: https://www.cdc.gov/salt/potassium.htm - last accessed 25 April 2021.
[22] Bhattacharya PT, Misra SR, Hussain M. Nutritional aspects of essential trace elements in oral health and disease: An extensive review. Scientifica [Cairo]. 2016; 2016:5464373. https://pubmed.ncbi.nlm.nih.gov/27433374/

[23] Schwartz ET, Holtorf K. Hormones in wellness and disease prevention: common practices, current state of the evidence, and questions for the future. Prim Care. 2008; 35 [4]: 669705. https://pubmed.ncbi.nlm.nih.gov/18928825/

[24] Yawoot N, Govitrapong P, Tocharus C, Tocharus J. Ischemic stroke, obesity, and the anti-inflammatory role of melatonin. Biofactors. 2021; 47 [1]: 41-58. Epub 2020 Nov 2. https://pubmed.ncbi.nlm.nih.gov/33135223/

[25] Brown GM. Light, melatonin and the sleep-wake cycle. $J$ Psychiatry Neurosci. 1994; 19 [5]: 345-53. https://pubmed.ncbi.nlm.nih.gov/7803368/

[26] Renfrew MJ, Lang S, Woolridge M. Oxytocin for promoting successful lactation. Cochrane Database Syst Rev. 2000; [2]:CD000156. https://pubmed.ncbi.nlm.nih.gov/10796158/

[27] Kumar R, Thompson JR. The regulation of parathyroid hormone secretion and synthesis. J Am Soc Nephrol. 2011; 22 [2]: 216-24. Epub 2010 Dec 16. https://www.ncbi.nlm.nih.gov/pmc/articles/PMC5546216/

[28] Nassar GN, Leslie SW. Physiology, Testosterone. [Updated 2021]. In: StatPearls. Treasure Island [FL]: StatPearls Publishing, 2021. Available https://www.ncbi.nlm.nih.gov/books/NBK526128/ - last accessed 25 April 2021.

[29] Dfarhud D, Malmir M, Khanahmadi M. Happiness \& health: The biological factors- systematic review article. Iran J Public Health. 2014; 43 [11]: 1468-77. https://www.ncbi.nlm.nih.gov/pmc/articles/PMC4449495/

[30] Berger M, Gray JA, Roth BL. The expanded biology of serotonin. Annu Rev Med. 2009; 60: 355-66. https://www.ncbi.nlm.nih.gov/pmc/articles/PMC5864293/

[31] Sprouse-Blum AS, Smith G, Sugai D, Parsa FD. Understanding endorphins and their importance in pain management. Hawaii Med J. 2010; 69 [3]: 70-1. https:/www.ncbi.nlm.nih.gov/pmc/articles/PMC3104618/

[32] Shinya H. The Enzyme Factor. Millichap Books, 2010.

[33] Haug A, Høstmark AT, Harstad OM. Bovine milk in human nutrition--a review. Lipids Health Dis. 2007; 6:25. https://www.ncbi.nlm.nih.gov/pmc/articles/PMC2039733/

[34] Ciccocioppo F, Lanuti P, Centonze D, Miscia S, Marchisio M. The link among neurological diseases: Extracellular vesicles as a possible brain injury footprint. Neurosignals. 2019; 27 [1]: 25-39. https://www.neuro-signals.com/Articles/000116/

[35] NICHD. What does the nervous system do? Eunice Kennedy Shriver National Institute of Child Health and Human Development. 2018. Available at: https://www.nichd.nih.gov/health/topics/neuro/conditioninfo/f unctions - last accessed 25 April 2021

[36] Olsson B, Lautner R, Andreasson U, et al. CSF and blood biomarkers for the diagnosis of Alzheimer's disease: A systematic review and meta-analysis. Lancet Neurol. 2016; 15 [7]: $\quad 673-84 . \quad$ Epub $2016 \quad$ Apr 8. https://pubmed.ncbi.nlm.nih.gov/27068280/ 
[37] Korfias S, Stranjalis G, Papadimitriou A, et al. Serum S-100B protein as a biochemical marker of brain injury: a review of current concepts. Curr Med Chem. 2006; 13 [30]: 3719-31. PMID:

17168733 .

https://pubmed.ncbi.nlm.nih.gov/17168733/

[38] Polich J, Kok A. Cognitive and biological determinants of P300: an integrative review. Biol Psychol. 1995 Oct; 41 (2): 103-46. doi: 10.1016/0301-0511(95)05130-9. https://pubmed.ncbi.nlm.nih.gov/8534788/

[39] Boulware DR, Hullsiek KH, Puronen CE, et al.; INSIGHT Study Group. Higher levels of CRP, D-dimer, IL-6, and hyaluronic acid before initiation of antiretroviral therapy
[ART] are associated with increased risk of AIDS or death. $J$ Infect Dis. 2011; 203 [11]: 1637-46. https://pubmed.ncbi.nlm.nih.gov/21592994/

[40] Rosano C, Marsland AL, Gianaros PJ. Maintaining brain health by monitoring inflammatory processes: a mechanism to promote successful aging. Aging Dis. 2012; 3 [1]: 16-33. Epub $2011 \quad$ Sep 30. https://pubmed.ncbi.nlm.nih.gov/22500269/

[41] Indrayan A. Aleatory and epistemic uncertainties can completely derail medical research results. J Postgrad Med. 2020; 66 [2]: 94-8. https:/www.ncbi.nlm.nih.gov/pmc/articles/PMC7239410/ 